\title{
Contrastive Study on Similarities and Differences between Chinese and English Characters
}

\author{
Xue Liu \\ School of Foreign Languages \\ Shandong Technology and Business University \\ Yantai, Shandong, China 264005
}

\begin{abstract}
Chinese and English belong to different language families. For a long time, it is generally believed that Chinese is "ideograph", English is "phonogram", and the differences between them are obvious, with very few similarities. This paper plans to start from the overall nature and function of the characters, to analyze the similarities of the two languages, and list other differences between the two languages besides the ideographic and phonetic differences.
\end{abstract}

Keywords-contrast of Chinese and English Characters; phonogram; ideograph; pictograph

\section{INTRODUCTION}

English belongs to the West Germanic branch of Germanic language group in the Indo-Europe language family. The origin and development of English is closely related to the development of the history of English-speaking people. English is the language of Anglo-Saxon of Great Britain, which is developed, enriched and gradually normalized and standardized under the influence of various factors. The basic language unit of English is a word spelled by letters.

Chinese belongs to the Chinese language group of SinoTibetan language family. What we are speaking is the common language and communication tool of the Chinese nation with Beijing pronunciation as the standard pronunciation, the dialect of north area as the basic dialect, and the typical modern vernacular works as the grammatical norms. The basic language unit of Chinese is Chinese characters.

Although the writing is originated from pictograph, it develops toward two different directions in the long-term evolution process, one is letter-spelled phonogram, and the other is pictograph with simple lines drawing the outline of things. Chinese and the western alphabetic writing belong to different language families. Pictograph and phonogram have their own strengths, showing the characteristics of common in differences, and difference within similarity. This paper intends to start from the overall nature and function of writing to analyze the common points and differences of the two languages.

\section{SimILARITIES IN CHINESE AND ENGLISH}

\section{A. Having the General Characteristics of Characters-Sound, Meaning and Form}

To reveal the nature that defining a character, first of all, the features of various characters in the world shall be learned, and then master the common characteristics of all characters, only in this way can the features that differing from the general characteristics and other features of the characters be revealed. Viewing the characters of various countries in the world, it is easy to see that the common characteristics of the characters in the world are reflected in three aspects:

1) All characters are the visible form symbols that act on vision: In other worlds, characters are tangible, for example, “Aa, Bb, Gg...”䜣 English, and “水，国，上，住，提…...”证 Chinese, these characters are the forms written by visible lines. The writing that cannot be seen by eyes is not character.

2) Any character has a fixed pronunciation: Any character represents a phoneme, or a syllable. For example, the English "A" is read as [ei], "B" is read as [bi:], Chinese “白” is read as "bai", “苍” is read as "cāng", “帆” is read as "fān". The pronunciation of a word is fixed for a long term, playing a role of marking the sound and recording the language.

3) The functional duties of all the characters are to express meaning: Each type of character takes its form (letter and stroke structure) and pronunciation as the medium, connecting with the basic element words of the language to convey thoughts and achieve the purpose of communication. The function of words and characters is to express ideals. In the characters in the world, some characters have their own meaning, such as Chinese characters; some characters do not express meaning except through appropriate phrases and collocations. For example, the single letters of "k.a.n.g.a.r.o.o" do not have meaning, but if they are organized into words as per the rules, such as "kangaroo", then they have meaning.

So on the whole, the common characteristics of all characters are that they are tangible, phonographic and ideographic. Any character is a tangible body, has pronunciation, and the final function and purpose is to express meaning for communication (although some single words themselves do not have meaning). Visible shape, sound, 
meaning is inherent in the three elements of the text. Therefore, morphology, phone and semantics are the three inherent elements of the characters, which can also be called the threedimensionality of characters.

\section{B. Source of all characters is pictograph}

The source of characters - both Chinese and Western, their earliest characters are pictographs, until the pictorial writing. As a result, at its source, it was difficult to determine whether an illustration is artistic portray or original character symbols.

The origin of Chinese characters can be traced back to two types of symbols about 8000 years ago: one is abstract and square shaped symbols represented by the inscriptions on the painted pottery in Dadiwan Site of Gansu Province; the other is the pictographic symbols represented by the inscriptions on oracle bones in Jiahu site in Henan Province. After 6,000 years of change, Chinese characters experienced Oracle, inscriptions on ancient bronze objects, small seal script, official script, regular script, and running script.

Just like Chinese characters are originated from pictographs, each letter in the English alphabet begins with a drawing depicting the shape of an animal or object, which eventually evolves into a symbol. But there are almost no similarities between these symbols and the originally depicted material objects. Our explanation is only the well-founded speculation made by the scholars based on historical materials. It is generally believed that the Greek alphabet is the ancestor of all the western letters (including the Latin alphabet). In fact, the letters of Greeks were borrowed from the Phoenicians.

On the $3500 \mathrm{BC}$ clay monument discovered in various regions in the Middle East and Southeast Europe, and the a large number of inscriptions left by Sumerians discovered in today's Iran and Iraq areas, there have the records such as land sale, commercial transactions and tax accounting. "It is noted that the symbols of these inscriptions coincide with the clay marks that had been used in the area for thousands of years when the characters haven't appeared. Among which, several marks of different shapes appear to have been used as counting system since at least 9000 BC." In the cuneiforms dated from around $4000 \mathrm{BC}$, some symbols developed from pictographs were used to mark phonetic factors. The earliest alphabetic writing-Semitic consonants appeared in 1700BC, which evolved into to 22 consonants of the Phoenician in $1200 \mathrm{BC}$. About $1000 \mathrm{BC}$, the Greeks converted the vowels into their own characters on the basis of the Phoenician alphabet. 700 $\mathrm{BC}$ to $600 \mathrm{BC}$, the Romans converted a variant of the Greek alphabet-Etruscan character into their own characters. With the foreign aggrandizement and conquest, the Roman alphabet, known as the Latin alphabet, spread to the vast areas of Western Europe, which was later popularized in the world because of the promotion of Christianity. As a result, the Latin alphabet became the originator the alphabets used by vast majority of countries. When the alphabet just appeared in other places in the world, the Chinese characters were at the Oracle stage.

In the Phoenician alphabet, the letter A read "aleph", and was written in the shape of letter $\mathrm{V}$ with a horizontal line in the middle, representing the head or horn of a cow. Later, the
Greeks wrote it upside down. For the ancient Phoenicians, cattle means wealth, as it was necessary for eating, wearing, and farming. This may be the reason why $\mathrm{A}$ is listed as the first letter.

$\mathrm{Bb}$ is the same as $\mathrm{A}$, as it can also be traced back to the ancient Phoenician. In the Phoenician alphabet, B was called beth, representing the house. In Hebrew, B was also called beth, also contained the meaning of housing. The letter B resembles the primitive society's two-room house, and the lower case letter $b$ is evolved from the capital letter B afterwards. In the West Bank of today's Jordan River, there is a Jewish Christian holy called Bethlehem. The word also contains the component of beth. In the alphabet, the reason why $\mathrm{B}$ is listed in the second position, may be that as for the survival of mankind, for the importance of residence is only next to food and clothing.

\section{GREAT DIFFERENCES BETWEEN BLOCK CHINESE CHARACTERS AND ENGLISH PHONETIC WORDS}

\section{A. Chinese Is Ideograph, English Is Phonogram}

Ideograph is a character system recording word or morpheme using symbolic writing symbols, which does not directly or simply indicate phone. As one of the earliest characters in the world, Chinese characters are still stay at the ideographic phase because of various reasons, becoming the only ideograph in the world, namely each word represents individual word or morpheme form. On the one hand, the meaning expression mode of Chinese characters is on the basis of pictographic writing, enabling the pure pictographic writing to gradually become the pure ideographic symbols; on the other hand, it creates pure ideographic symbols, or use the existing pictographic characters, with the addition of other symbols to represent new meaning, such as "上, 三, 出, 至, 明, 林" and so on, which are of large quantity. Although more than $90 \%$ of the pictophonetic characters in modern Chinese characters are of phonographic elements, such as the pictophonetic characters "羊, 王, 胡, 张" of "洋, 汪, 湖, 涨 ", they are not free from ideographic meaning. On the one hand, the semantic radical " $\%$ " retains obvious role of meaning-expression, on the other hand, the phonetic radical itself is often an ideographic word that can be used alone, which is occasionally borrowed to express the pronunciation of some words, and that can only be said that Chinese characters have a sound tendency, but have essential differences with phonogram. Ideograph has a greater adaptability, as it can be directly used with fonts by people of different times and from different dialect areas regardless of ancient and modern phonetic changes and differences of dialects. However, ideograph also has shortcomings. Even a word or a morpheme has to be recorded, and the character itself cannot directly represent sound, making both learning and use difficult.

Phonogram is a writing system that uses a written sign, or alphabet, to represent the pronunciation of a word. Its written symbol is neither physical image nor the meaning unit that directly represents word or morpheme, but only the smaller phonetic unit without meaning. Therefore, phonogram is directly linked to the phonetic material of language. People will be able to identify the words or morphemes represented by 
them based on the pronunciation combined with letters of phonogram. As a result, corresponding meaning unit can be recorded and expressed via phonetic unit. There are very few small phonetic units in language, so there are relatively less writing symbols of phonogram, which is far from complex like ideograph, and it is more convenient to master and use. Many modern nations use phoneme characters, including English, German, Russian, French and other languages that use phoneme characters, or the phonemic language of Turkish that trams from the original consonants of Arabic alphabet to Latin alphabet. Now, the phoneme characters are also used in Chinese phonetic alphabet.

\section{B. The Ideogram of Chinese Characters Determines the Chinese Characters to Attach Importance to Vision; the Phonetic Feature of English Determines English to Emphasize Hearing}

Chinese characters are created based on Liu Shu (Six Ancient Categories of Chinese Characters), but all of them create characters on the basis of "pictographic" character first of all. Although the pictographic characters that are originated from pictographic drawing for recording have got rid of the features of pictographic drawing and been transformed into abstract symbols after $\mathrm{Li}$-character evolution and development of regularized characters, the strokes such as dot stroke, horizontal stroke, vertical stroke, left-falling stroke, rightfalling stroke, rising stroke, turning stroke, and hook stroke still remain the traces of pictograph. The characters created with such strokes are of unique shape with very high aesthetic value. At the same time, each character is formed with one of the theoretical bases of Liu Shu. Thus the learners may have certain memory clues as each character is creased by certain principle of characters.

The square Chinese characters have the shape structure with theoretical basis and aesthetic value, thus the unique Chinese calligraphy art is formed. Calligraphy refers to write using the chirography style, technique of writing, structure and art of composition according to characters' characteristics and meaning, to make it an artistic work full of beauty. The great charm of Chinese calligraphy art is mainly manifested in two aspects: one is its charm and artistic conception, the other is its extremely rich ideological content. It is precisely because of the two aesthetic characteristics of Chinese calligraphy art, and the two are highly integrated. Therefore, Chinese calligraphy art is honored as silent poetry, dance without line, painting without images and music without sound.

In English, there is the word "Calligraphy", having its explanation in English dictionary as "beautiful handwriting." However, the performance image of phonogram is very limited, because the letters are used repeatedly in horizontal arrangement. So they show relatively simple visual effects in terms of presentation. This is the limitation of phonogram. Therefore, some foreign art historians say that Chinese characters themselves have a very rich graphic beauty. Every Chinese character is like an abstract sculpture, having a natural artistic quality.

\section{Chinese Characters Have Combination of Characters, English Has Words without Characters}

As for ideographical expression, the biggest feature of Chinese characters is combination of characters and phrases. That is, each character is a word with complete meaning. Throughout the Chinese dictionaries, we can find that the single character of vast majority of Chinese characters (more than $99 \%$ ) itself is a word with meaning that can be used freely. Therefore, in the Chinese written language, the character is not like the Western phonetic alphabet which is just a symbol representing phoneme, but more importantly, at the same time, it is also a word carrying meaning. This feature can be said unique in various characters of the world. Some people say that Chinese characters represent only morphemes but not words. Throughout the whole "Xinhua Dictionary", most characters can be used as words. In modern Chinese, many disyllable words, the so-called "compound words" in modern Chinese are actually compound words composed of two meanings. For example, 声音, 选择, 眉目, 始终, 方圆, 车, 笔直, 提高, 阐明, 书本, 枪支, 举重, 注意, 理事, 地震, 自 卫 $\cdots$, these words are actually composed of two characters, which is a complex of two meanings. These disyllable compound words can be used separately. Such as the word "选 择", take "选" as a monosyllabic word, such as "任你选一个", and only "取" can also be used, such as "择其要者". The meaning of each character of such word is called "morpheme (词素)", and later with the influence of morpheme (语素) theory of foreign linguistics, it is called morpheme (语素). Because every single character in Chinese is a meaningful monosyllabic word, so the Chinese dictionary is actually a collection of Chinese monosyllabic words. In fact, the Chinese dictionary is also a book offering phonetic symbols and interpretation to each Chinese character. Why Chinese characters can be interpreted one by one? It is just because that every single character is a word. On the contrary, why the English, French and other countries using the alphabet only have dictionaries (wordbooks)? The reason is letters do not have meaning with necessity to be interpreted. In Chinese, two monosyllabic words can be selected to form a compound word, and a monosyllabic word and a compound word are the language units of same level. In Chinese, "选" is a word, "择" is a word, and "选择", the combination of them is still a word. Thus, the vast majority of Chinese characters themselves are words. Homobody (or integration) of character and word is the most fundamental difference between Chinese characters and other languages.

\section{Development and Changes of Chinese and English Are Different}

English and Chinese have gone through thousands of years of development and changes. In the history, English has suffered foreign invasion repeatedly by many ethnic groups, as well as several great influence and impact in terms of development of the language. Ancient English was influenced by the ancient Greek civilization; in 43 BC, Julius Caesar conquered Britain, the Romans ruled the United Kingdom, brought their Latin here; Germanic people landed England in the year 449, bringing their Germanic to England, which was developed into the present English; The Norman Conquest in 
1066 made French the language of British upper class, and these French borrowed words cover almost all the life language and abstract concepts of the upper class. More than ten thousand words of Middle English were borrowed from French; the Renaissance re-aroused the study of Latin and ancient Greek, and later, with the development of the United Kingdom and the worldwide colonial expansion, English was constantly affected by foreign language. In modern English words, many stems and affixes are deeply imprinted with foreign words. For example, "epilog" correspondingly retains the prefix "epi" and root "log" of Greek "epilogos", "credible" retains the Latin word "credi-", and "empire, crown, pedition" directly come from French. These distinctive borrowed words make English vocabulary very abundant, and bring a lot of affixes with a broad use.

From the initial Oracle to the current regular script, Chinese characters have also gone through several evolutions, with constant changes in glyphs and meaning, and it cannot be verified how some associative characters express meaning. However, in the history of thousands of years, China was in a closed and conservative state for most of the time, without much or direct contact with other countries, and there have been no too many alien invasions or dominations by foreign nations. Therefore, different from English, Chinese characters are in a situation of self-development and improvement for most of the time.

In the recent centuries, China gradually opened its doors and increased its communication with the outside world, so Chinese characters began to be affected by foreign languages, and some foreign language has also entered the Chinese vocabulary. However, these influences are different from those of foreign languages on English words. Many new words and affixes appeared in English, unlike English, the structure of Chinese characters did not changed a lot, only some new Chinese characters appeared, and some original ones were granted with new meaning. In addition, many of the existing Chinese characters combine to express new meaning.

\section{CONCLUSION}

For a long time, it is generally believed that Chinese is "ideograph", English is "phonogram", with obvious differences and few similarities. Through the analysis of this paper, we can easily see that, as a written form of language, the Chinese and English languages have common characters, and both the square Chinese characters and English letters are originated from hieroglyphs. The differences between the two languages are not only reflected in the nature of "phonetic" and "ideographic", but there are also significant differences in writing, aesthetics, lexical composition and character development.

\section{REFERENCES}

[1] Bough, Albert C. and Thomas Cable, A History of the English Language, Beijing: Foreign Language Teaching and Research Press, 2000 .

[2] Humboldt Wilhelm Von. On the Comparative Study of Language and Its Relation to the Different Periods of Language Development. In
Harden and D. Farrelly (eds), Essays on Language/Wilhelm Von Humboldt, Frankfurt and Main, Lang. 1997.

[3] Cai Yongfei, Wang Zhiguang. Comparative Study on Chinese and English Characters. Zhejiang University Press, 2005.

[4] Huang Weixing, Zhang Yuneng. Art of Composition of Chinese Characters and Thinking Mode of Chinese Nation [J]. Journal of Shaanxi Normal University (Philosophy and Social Sciences Edition), 2016 (03).

[5] Mou Zuowu. Origin of Ancient Chinese Characters [M]. Shanghai: Shanghai People 's Publishing House, 2000.

[6] Pan Wenguo. Comparison Outline of Chinese and English [M]. Beijing: Beijing Language and Culture Publishing House, 2002.

[7] Sun Junxi. History of Chinese Characters [M]. Beijing: Academy Press, 1991.

[8] $\mathrm{Xu}$ Lulu, Wu Jin. Contrastive Analysis of English and Chinese Characters [J]. Journal of Educational Institute of Jilin Province, 2012 (10).

[9] Yi Lixin. Contrastive Study of English and Chinese Writing System and Chinese and Western Modes of Thinking [J]. Journal of South-Central University for Nationalities (Humanities and Social Sciences), 2004 (01).

[10] Zhou Youguang. A History of Development of Writing, Shanghai Education Press, 2003. 